\title{
Role of Anti-SARS-CoV-2 antibodies in different cohorts: Can they provide clues for
} appropriate patient triaging?

\author{
Manohar B. Mutnal ${ }^{1}$, Amin A. Mohammad ${ }^{1}$, Alejandro C. Arroliga ${ }^{2}$, Yinan Hua ${ }^{1}$, Liping Wang ${ }^{1}$ \\ William Koss ${ }^{1}$, Arundhati Rao ${ }^{1}$ \\ Author affiliation:
}

1. Department of Pathology and Laboratory Medicine, Baylor Scott \& White Medical Center, 2401 South $31^{\text {st }}$ Street, Temple, TX 76508

2. Department of Pulmonary Medicine and Critical Care and Chief Medical Officer, Baylor Scott \& White Medical Center, 2401 South $31^{\text {st }}$ Street, Temple, TX 76508

Address for correspondence

Manohar B. Mutnal, Ph.D.

Section Chief - Microbiology

Department of Pathology and Laboratory Medicine

2401, South $31^{\text {st }}$ street, Temple TX 76508

manohar.mutnal@bswhealth.org

Phone: 254-724-2714

Short title: Diagnostic and clinical utility of anti-SARS-COV-2 antibodies 


\section{Abstract:}

The emergence of coronavirus disease 2019 (COVID-19) has become a major global health crisis. Currently, diagnosis is based on molecular techniques, which detect the viral nucleic acids when present at detectable levels. The serum IgG response against SARS-CoV-2 was examined by using an ELISA-based assay. Serum samples, along with nasopharyngeal specimens were collected from various cohorts and analyzed by ELISA and rRT-PCR, respectively. A total of 167 serum samples were tested for serum IgG antibodies against SARSCoV-2 in outpatient cohorts, 15 (8.9\%) were positive by rRT-PCR and the remaining $152(91 \%)$ were negative. We used these data to generate two different assay cutoffs for serum IgG assay and investigated percent concordance with rRT-PCR test results. The emergency department data revealed, out of 151 nasopharyngeal swabs, 4 (2.6\%) were positive by rRT-PCR and 18 (11.9\%) were positive for serum IgG assay. Among the 18 patients that were positive for serum IgG, 13

35 (72.2\%) exhibited 1-3 symptoms of COVID-19 and $5(27.7 \%)$ patients did not present with any COVID-19 related symptoms, per CDC criteria. All 4 (100\%) patients that were positive by rRT-

37 PCR had symptoms of COVID-19 disease. A longitudinal study from the inpatient population suggested there was a sharp increase in the serum IgG titers in 5 patients, a moderate increase in 1 patient and a plateau in 3 patients. Sero-prevalence of COVID-19 disease in pre-procedure patients was $5.5 \%$. Our findings suggest serological tests can be used for appropriate patient

41 triaging when performed as an adjunct to existing molecular testing. 


\section{Introduction}

In December 2019, a series of pneumonia cases of unknown cause emerged in Wuhan, Hubei, China, with clinical presentations greatly resembling viral pneumonia ${ }^{1}$. Subsequently, pathogenic gene sequencing identified the infecting pathogen as a novel coronavirus, named Severe Acute Respiratory Syndrome Coronavirus-2 $(S A R S-C o V-2)^{2}$. It has been listed as a public health emergency of international concern, and, following declaration of a pandemic by the World Health Organization (WHO), governments worldwide have taken drastic measures to contain the outbreak, including the quarantine of millions of residents in many countries.

According to the Centers for Diseases Control and Prevention (CDC, Atlanta, GA, USA) and recent reports, most COVID-19 patients have an incubation period of 2 to 14 days ${ }^{3}$. CDC has listed 11 symptoms for clinical diagnosis. Fever, cough, shortness of breath and fatigue are the most common symptoms, whereas nasal congestion and diarrhea are only noted in a small number of patients ${ }^{4}$. Severe cases might progress to acute respiratory distress syndrome (ARDS), septic shock and difficult-to-tackle metabolic acidosis, and bleeding and coagulation dysfunction. Some COVID-19 patients have only mild or atypical symptoms, including, initially, even some of those who go on to develop severe and critical cases ${ }^{4}$. The chest computed tomography of COVID-19 patients is characterized by the ground-glass opacity and bilateral patchy shadowing ${ }^{5}$. For laboratory tests, it has been reported that most patients had lymphopenia and elevated C-reactive protein ${ }^{6}$. However, these clinical and laboratory characteristics are not easily distinguishable from pneumonia induced by infection with other common respiratory tract pathogens.

The appropriate and accurate diagnosis of the SARS-CoV-2 infection is critical for epidemiological interventions to prevent further spread within the community ${ }^{7}$. Currently, 
molecular testing remains the only testing method for detection of virus RNA from nasopharyngeal specimens collected from suspected cases. Like many other diagnostic methods, molecular testing comes with some degree of variability with respect to sensitivity and specificity, mainly driven by the pre-analytical steps and kinetics of virus shedding from the infected individuals. For example, studies show discordant results from different types of specimens collected, naso- vs. oro-pharyngeal swabs, in COVID-19 patients ${ }^{8}$. Additionally, many cases that show strong epidemiologic links to $S A R S-C o V$-2 exposure and with typical lung

72 radiological findings remain RNA negative in their upper respiratory tract samples. The

73 performance of molecular tests thus depends on many factors, including the sample type ${ }^{9}$, the

74 patient's stage of infection ${ }^{10}$, the skill of sample collection, and the quality and consistency of

75 the PCR assays being used. Any of these factors can lead to a substantial delay in early diagnosis

76 and management, in turn delaying both timely life support treatment for the individual and

77 contact tracing and preventive quarantine to contain virus spread ${ }^{11}$.

Antibody detection tests offer the opportunity to mitigate some of the challenges molecular testing presents. They have faster turn-around time, high throughput, and cost less per test compared to molecular testing, and thus may be a valuable adjunct where challenges to

81 timely results and/or quality sample collection for molecular testing arise.

83 Coronavirus infections. They have only rarely been utilized for diagnosis of common cold

84 Coronavirus infections, hence many laboratories lack experience in serological testing for new $S A R S-C o V-2$ and may encounter initial problems with test performance characteristics and 
We investigated the performance of an ELISA test for anti-SARS-CoV-2 antibody

88

89

90

91

92

detection, the relationship of molecular tests with serological tests in outpatient specimen and

concurrently collected emergency department and pre-procedure specimens, and the dynamics of anti-SARS-CoV-2 antibody responses in a small sample of serially-collected blood samples from

inpatients with confirmed COVID-19. Further, we discuss the value and potential diagnostic and clinical use of serological test as an adjunct to molecular testing in these various cohorts.

\section{Methods:}

This study was reviewed and approved by the Baylor Scott and White Research Institute (BSWRI) Institutional Review board (IRB \# 020-122)

\section{Study design and specimen source:}

This study included outpatient, emergency department, inpatient and pre-procedure adult patients from Baylor Scott \& White Medical Center in Temple (Temple, TX). All adult patients were screened for symptoms of SARS-CoV-2 infection according to WHO and Baylor Scott \& White Health (BSWH) guidelines, except pre-procedure patients.

\section{Outpatient specimens:}

Serum samples from 167 patients were collected and stored at $-20^{0} \mathrm{C}$ until tested. Specimens were collected from patients presenting at BSWH outpatient clinics with suspected symptoms of $S A R S-C o V-2$ infection. Of the 167 patients, 15 (8.9\%) were confirmed positive by rRT-PCR for SARS-CoV-2 infection, and serum specimens from rRT-PCR confirmed patients were drawn at $\geq 13$ days after rRT-PCR test results. Additionally, 33 (19.7\%) specimens were collected $\leq 13$ days after initial rRT-PCR testing. $152(91 \%)$ serum specimens were from patients who tested negative by rRT-PCR. 
Emergency department (ED) specimens:

111 visited the ED with suspected symptoms of $S A R S-C o V-2$ infection. Specimens were collected

112 from patients who exhibited at least one symptom related to COVID-19 disease as indicated by

113 CDC. Symptoms included, fever, chills, cough, shortness of breath or difficulty breathing,

114 fatigue, muscle or body aches, headache, new loss of taste or smell, sore throat, congestion or

115 runny nose, nausea or vomiting, and diarrhea.

116 Inpatient specimens:

Several ED patients were transitioned to inpatient status due to clinical necessity.

118 Residual serum specimens from 9 SARS-CoV-2 confirmed inpatients were collected over a

119 period of their stay in the hospital and analyzed for serum IgG.

Pre-procedure specimens:

On April 22, 2020, BSWH reopened elective surgical procedures and established a

122 screening protocol for $S A R S-C o V-2$ infection. Elective surgery patients were required to submit a

123 nasopharyngeal swab and an optional blood sample for serological testing. Accordingly, 6,271

124 paired nasopharyngeal swabs and blood samples were submitted by the weekend of June 12 ,

125 2020. Pre-procedure specimens can be considered truly random in distribution and represented 126 the central Texas general population.

127 Pre-COVID-19 specimens: 
One hundred pre-COVID-19 serum samples were selected from the BSWH specimen

129 biobank for specificity testing of the serum IgG assay. These specimens were collected during 2018-19 Influenza season.

Data collection and analysis:

Clinical and laboratory data were extracted from electronic medical records and the laboratory information system. The receiver operating characteristic (ROC) curve plots the sensitivity against 1-specificity, or true positive rate vs. false positive rate, for all the possible cutoffs. Based on a visual assessment of the ROC curve, two potential cutoffs were chosen to calculate the sensitivity and specificity compared to rRT-PCR results. The final assay cutoff for serological testing was prepared using outpatient test results. ROC analysis and data visualization were done using EP evaluator software (Data innovations, South Burlington, VT, USA).

\section{Laboratory procedures}

Molecular testing for SARS-CoV-2 infection:

Methods for laboratory confirmation of SARS-CoV-2 infection were based on the rRTPCR technique approved by the US Federal Drug and Food Administration (FDA) under an Emergency Use Authorization (EUA) ${ }^{7}$. Briefly, all BSWH specimens were collected either at drive through collection sites, emergency department or from inpatients using a flocked swab in Universal or Transport Media (Copan Technologies, USA). Specimens were transported at 2 - 8 ${ }^{\circ} \mathrm{C}$ to the BSWH-Temple molecular pathology laboratory for processing and testing with less than 3 hours of transit time. The BSWH-Temple molecular pathology laboratory was responsible 
149 for $S A R S$ - $C o V$-2 detection in respiratory specimens by rRT-PCR methods (Luminex

150 Corporation, Austin, TX USA).

The SARS-CoV-2 primers were designed by Luminex to detect RNA targets from the $S A R S-C o V-2$ in respiratory specimens from patients, as recommended for testing by public

153 health authority guidelines. Luminex Aries employs primers for amplifying the ORF1 gene and 154 the $N$ gene from the $S A R S-C o V$-2 virus, and the assay includes extraction and internal controls 155 (Human RNAase P) built into the same cartridge, to verify sample lysis, nucleic acid extraction, 156 and proper system and reagent performance. Luminex Aries offers true random-access testing, 157 unlike the Luminex NxTAG platform, an assay for batched testing (offering high throughput 158 capabilities) on which increased demand for testing necessitated verification and 159 implementation. The Luminex NxTAG method also includes an additional Envelope $(E)$ gene target for SARS-CoV-2 detection.

Serum samples were collected, as stated above, from both PCR positive and negative patients, and tested for anti-SARS-CoV-2 IgG antibodies. Testing was performed as per the 164 instructions for use provided by the manufacturer. Briefly, the $S A R S-C o V-2$ IgG assay (Ansh Laboratories, Houston, TX, USA) uses indirect two-step immunoassay methods. In the assay, calibrators and unknowns were incubated in microtiter wells coated with purified SARS-CoV2 recombinant antigens (spike and nucleocapsid). After incubation and washing, the wells were treated with the conjugate, composed of anti-human IgG antibodies labeled with peroxidase.

169 After a second incubation and washing step, the wells were incubated with the substrate tetramethylbenzidine (TMB). An acidic stopping solution was then added and the degree of

171 enzymatic turnover of the substrate is determined by wavelength absorbance measurement at 450 
$172 \mathrm{~nm}$ as primary test filter and $630 \mathrm{~nm}$ as reference filter. The absorbance measured is directly

173 proportional to the concentration of human IgG antibodies present in the specimen. The serum

174 IgG ELISA method was automated on Dynex DSX 4-plate instrument (Dynex Technologies,

175 Chantilly, VA, USA). Calibrators and controls were run as per the manufacturer's

176 recommendations provided in the package insert.

178 assay uses a three-point calibration curve. Performance characteristics were established in

179 accordance with regulatory requirements and are available for review. During internal

180 validations sensitivity of $95 \%$ and specificity of $98.3 \%$ were established at the time of test

181 implementation. In this study, we used 100 pre COVID-19 specimens for additional specificity

182 testing.

\section{Sample dilution experiment}

In order to rule out non-specific binding, specimens that tested positive by ELISA assay

185 were diluted using sample diluent provided in the assay kit. Specimens were diluted 1:2, 1:4, 1:8

186 and 1:16 and were re-tested along with an undiluted specimen. Percent recovery was calculated

187 and plotted. 


\section{Results:}

Outpatient serological testing experience and test performance:

A total of 167 serum samples were tested for serum IgG antibodies against SARS-CoV-2; concordance with rRT-PCR test results.

At a lower assay cutoff, $13 \mathrm{AU} / \mathrm{mL}$, there was a $22.3 \%$ concordance with rRT-PCR assay cutoffs, compared to rRT-PCR (Tables 1A and 1B).

Additionally, 15 serum specimens that were collected $\geq 13$ days after initial positive rRT-

PCR test had $100 \%$ concordance with the serum IgG assay, however, 33 (19.7\%) serum IgG antibodies with zero percent concordance with rRT-PCR. 
we were also able to determine the assay cutoff: using outpatient derived serology test results, the cutoff was set at $13 \mathrm{AU} / \mathrm{mL}$ using EP evaluator software (Fig. 2).

Specificity of the serum IgG assay was determined using pre-COVID-19 archived serum specimens. Among the 100 pre-COVID-19 specimens, none were reactive on the IgG assay, further confirming the specificity of the assay at $100 \%$. This also meant that negative predictive value of the assay was $100 \%$ at the lower assay cutoff.

\section{Emergency department serological testing experience}

ED specimens, both nasopharyngeal swabs for rRT-PCR and serum for IgG assay, were concurrently collected and tested. Out of 151 nasopharyngeal swabs, 4 (2.6\%) were positive by rRT-PCR and $18(11.9 \%)$ were positive for serum IgG assay. Among the 18 patients that were positive for serum IgG, 13 (72.2\%) exhibited 1-3 symptoms of COVID-19 and 5 (27.7\%) patients did not present with any COVID-19 related symptoms, per CDC criteria (Table 3A). Similarly, all 4 (100\%) patients that were positive by rRT-PCR had symptoms of COVID-19 disease (Table 3B). Both serology and rRT-PCR tests were negative for $53(39.8 \%)$ and 59 (40\%), respectively, patients who exhibited 1 or more COVID-19 related symptoms.

Patients exhibiting COVD-19 related symptoms had a concordance of $72.2 \%$ with serum IgG assay results, providing an opportunity to consider the patients as potential SARS-CoV-2 infections for triaging to appropriate COVID-19 designated wards if there was clinical necessity, especially in the absence of positive rRT-PCR test results and with the high negative predictive value of the serological test. 
These ED data provide an opportunity for preventing spread of infection in the non-

231

232

233

\section{Inpatient serological testing experience:}

Many of the ED patients were admitted as inpatients, provideing an opportunity for a limited longitudinal study on the serum IgG titers from residual specimens. Data presented in Fig. 3 show that there was a moderate to high increase in the serum IgG titers for a few patients within a very short period. Among the 9 patients that were followed, 5 demonstrated a sharp increase in the IgG titers within 1-3 days of initial testing (patient numbers 1, 2, 4, 6 and 7). There was moderate increase in the IgG titers for one patient (patient number 5) while the IgG levels had plateaued in 3 patients (patient numbers 3, 8 and 9).

\section{Titers of SARS-CoV-2 antibodies can reflect the progress of viral infection. A sharp} increase in the titers within a short period suggests an ongoing and active infection; therefore, these patients needed to be placed in COVID-19 designated wards to prevent cross contamination. The conventional belief, for many infections, is that a rise in the serum antibody titers corroborates an enduring infection.

\section{Pre-procedure serological testing experience:}

As mentioned in the methods, a total of 6,271 rRT-PCR and serum IgG tests were performed by the end of June 12, 2020. Among the 6,271 rRT -PCR tests, 60 (0.95\%) were positive. Serum IgG test was positive for 351 (5.5\%) patients among the patients who submitted paired specimens for pre-procedure screening. Since the pre-procedure patient population 
251 represented a random group from various parts of the central Texas region, we estimated sero-

252 prevalence of COVID-19 to be at $5.5 \%$ in this part of the nation.

Pre-procedure serological testing data clearly suggested a higher prevalence of COVID-

25419 compared to rRT-PCR data. These findings, combined with other clinical symptoms and

255 laboratory findings, may allow careful decision making for downstream procedures, such as

256 rescheduling or use of enhanced personal protective equipment during the invasive procedure.

\section{Discussion}

Testing for SARS-CoV-2 RNA has become the standard for COVID-19 diagnosis ${ }^{12}$.

259 However, a number of false negative results have been reported, resulting in a failure to

260 quarantine infected patients ${ }^{12}$. If unchecked, this could cause a major setback in containing viral

261 transmission ${ }^{13}$. Serological tests are crucial tools for assessments of SARS-CoV-2 exposure,

262 infection and potential immunity. Their appropriate use and interpretation requires accurate assay

263 performance data ${ }^{14}$.

We described the use of serological testing for $S A R S-C o V-2$ infection in various

265 healthcare contexts, examining outpatient, emergency department, inpatient, and pre-procedure

266 patients. Outpatient data were utilized to determine the performance characteristics of the IgG

267 ELISA assay, which was validated and implemented as a laboratory-developed test. Two assay

268 cutoffs were established based on its performance compared to rRT-PCR method. Both the

269 cutoffs provided a nearly $100 \%$ negative predictive value.

271 probabilities, however, serological tests with high specificity and negative predictive value can 
272 be used as an adjunct to rRT-PCR findings, combined with other clinical symptoms and

273 laboratory findings for appropriate patient care.

Increased virus shedding and transmission have been reported in people asymptomatic

275 for COVID-19 ${ }^{10}$.rRT-PCR findings combined with serological testing can further delineate

276 different types of infected people, including asymptomatic individuals. We have shown here that

277 both pre-procedure (asymptomatic) and ED (symptomatic) patients had higher positivity rates by

278 serological testing than rRT-PCR, including several of ED patients who were symptomatic as per

279 the CDC definition of COVID-19. nasopharyngeal swabs could be below detectable levels. The long incubation time allows for antibody development in the infected individual, and both serum $\operatorname{IgM}$ and $\operatorname{IgG}$ would begin to appear at levels detectable by commercial assays ${ }^{13}$. It is therefore important to have an assay that has high specificity, sensitivity and negative predictive value, such as the one used here. In this study, 13 (72\%) out of 18 of the patients in ED were found to have COVID-19 specific symptoms and tested positive for serum IgG, indicating an ongoing infection.

291 based on the increase in the titer of specific antibodies. Several infectious diseases are diagnosed 292 based on serological tests and the diagnosis is often based on the demonstration of an increase in 293 the serum antibody levels between acute and convalescent specimens ${ }^{15}$. We strongly believe that 
294 a similar diagnostic approach is necessary for a largely unknown entity such as COVID-19,

295 perhaps with a short duration between specimens collected, as demonstrated in this study.

High specificity testing is crucial in low-prevalence settings, as shown in our data; the

297 ELISA test we employed had $100 \%$ specificity with a negative predictive value of $100 \%$. We

298 evaluated 6000+ serum and nasopharyngeal swabs from pre-procedure patients and found that

299 the positivity rate was significantly higher by serological test than rRT-PCR. These pre-

300 procedure patients were asymptomatic and represented a true random sample from the central

301 Texas region. We observed 5.5\% sero-prevalence in this region. Serological tests thus have a

302 significant role in downstream clinical decision-making (use of enhanced PPE or rescheduling)

303 and patient triaging to appropriate care and/or discharge.

The intent of this study was not to provide any guidelines or recommendations on how to

305 use anti-SARS-CoV-2 serological tests in various settings, especially since the CDC recommends

306 that serological tests alone should not be used for diagnosis. However, the CDC also

307 recommends that, in certain situations, serologic assays may be used, in conjunction with viral

308 detection tests, to support clinical assessment of persons who present late in their illnesses ${ }^{3}$. We

309 recommend that it is best left to the discretion of individual healthcare facilities and the

310 preference of scientific community as to what the specific downstream applications of

311 serological tests may be in the management of COVID-19.

\section{Conclusion:}

We demonstrated how an adjunct serological test with high negative predictive value for

$314 S A R S-C o V-2$ infection can be leveraged for appropriate clinical decision making in various

315 clinical scenarios. 
bioRxiv preprint doi: https://doi.org/10.1101/2020.06.26.174672; this version posted June 29, 2020. The copyright holder for this preprint (which was not certified by peer review) is the author/funder. All rights reserved. No reuse allowed without permission.

316 Acknowledgment: Authors sincerely thank Jeffry Hunt for help with data extraction, Courtney Shaver

317 for statistical help and Briget Da Graca for editorial help. 


\section{References:}

1. World Health Organization. Coronavirus disease (COVID-19) pandemic. Accessed June 23, 2020. https://www.who.int/emergencies/diseases/novel-coronavirus-2019

2. Zhou F, Yu T, Du R, et al. Clinical course and risk factors for mortality of adult inpatients with COVID-19 in Wuhan, China: a retrospective cohort study. Lancet. 2020;395(10229):1054-1062. doi:10.1016/S0140-6736(20)30566-3

3. Centers for Disease Control and Prevention. Overview of Testing for SARS-CoV-2. Accessed June 23, 2020. https://www.cdc.gov/coronavirus/2019-ncov/hcp/testingoverview.html

4. Huang Y, Tu M, Wang S, et al. Clinical characteristics of laboratory confirmed positive cases of SARS-CoV-2 infection in Wuhan, China: A retrospective single center analysis [published online ahead of print, 2020 Feb 27]. Travel Med Infect Dis. Published online February 27, 2020:101606. doi:10.1016/j.tmaid.2020.101606

5. Chen C, Li H, Hang W, Wang DW. Cardiac injuries in coronavirus disease 2019 (COVID19). J Mol Cell Cardiol. 2020;145:25-29. doi:10.1016/j.yjmcc.2020.06.002

6. Chen N, Zhou M, Dong X, et al. Epidemiological and clinical characteristics of 99 cases of 2019 novel coronavirus pneumonia in Wuhan, China: a descriptive study. Lancet. 2020;395(10223):507-513. doi:10.1016/S0140-6736(20)30211-7

7. Mutnal MB, Arroliga AC, Walker K, et al. Early trends for SARS-CoV-2 infection in central and north Texas and impact on other circulating respiratory viruses [published online ahead of print, 2020 May 15]. J Med Virol. Published online May 15, 2020. doi:10.1002/jmv.26010

8. Wang W, Xu Y, Gao R, et al. Detection of SARS-CoV-2 in Different Types of Clinical Specimens. JAMA. 2020;323(18):1843-1844. doi:10.1001/jama.2020.3786

9. Chan JF-W, Yuan S, Kok K-H, et al. A familial cluster of pneumonia associated with the 2019 novel coronavirus indicating person-to-person transmission: a study of a family cluster. Lancet. 2020;395(10223):514-523. doi:10.1016/S0140-6736(20)30154-9

10. Zou L, Ruan F, Huang M, et al. SARS-CoV-2 Viral Load in Upper Respiratory Specimens of Infected Patients. N Engl J Med. 2020;382(12):1177-1179. doi:10.1056/NEJMc2001737

11. Zhao J, Liao X, Wang H, et al. Early virus clearance and delayed antibody response in a case of COVID-19 with a history of co-infection with HIV-1 and HCV [published online ahead of print, 2020 Apr 9]. Clin Infect Dis. 2020;ciaa408. doi:10.1093/cid/ciaa408

12. Li Z, Yi Y, Luo X, et al. Development and clinical application of a rapid IgM-IgG combined antibody test for SARS-CoV-2 infection diagnosis [published online ahead of 
365

366

367

368

369

370

371

372

373

374

375

376

377

378

379

380

381

382

print, 2020 Feb 27]. J Med Virol. Published online February 27, 2020.

doi:10.1002/jmv.25727

13. Guo L, Ren L, Yang S, et al. Profiling Early Humoral Response to Diagnose Novel Coronavirus Disease (COVID-19). Clin Infect Dis. Published online March 21, 2020. doi:10.1093/cid/ciaa310

14. Whitman JD, Hiatt J, Mowery CT, et al. Test performance evaluation of SARS-CoV-2 serological assays. Preprint. medRxiv. 2020;2020.04.25.20074856. doi:10.1101/2020.04.25.20074856

15. Miller JM, Binnicker MJ, Campbell S, et al. A Guide to Utilization of the Microbiology Laboratory for Diagnosis of Infectious Diseases: 2018 Update by the Infectious Diseases Society of America and the American Society for Microbiology. Clin Infect Dis. 2018;67(6):e1-e94. doi:10.1093/cid/ciy381

65

7

8

9

0

71

2

33

74

75

76




\section{Figure legends:}

384 Fig 1.

385 ELISA method used in the study was verified for its specificity and non-specific binding as

386 described in the methods. Five discordant samples from outpatient specimens were serially

387 diluted and tested on the ELISA method. Specimen tested exhibited a linear decrease in the IgG

388 concentration and percent recovery of the analyte is shown below in the data table.

$390 \quad$ Fig 2.

391 Using outpatient data and ROC analysis an assay cutoff of $13 \mathrm{AU} / \mathrm{mL}$ was calculated. ROC was

392 determined using EP evaluator software.

394 Figure 3.

395 Residual serum specimens were available for 9 in-patients who were followed-up for serum $\operatorname{IgG}$

396 titers over the period of their hospital stay. Serum IgG titers were determined using ELISA

397 method as described in the methods and $\mathrm{AU} / \mathrm{mL}$ is plotted against the time. Data presented in the 398 table represents actual titers for specific patients vs. time. 
bioRxiv preprint doi: https://doi.org/10.1101/2020.06.26.174672; this version posted June 29, 2020. The copyright holder for this preprint (which was not certified by peer review) is the author/funder. All rights reserved. No reuse allowed without permission.

Fig. 1

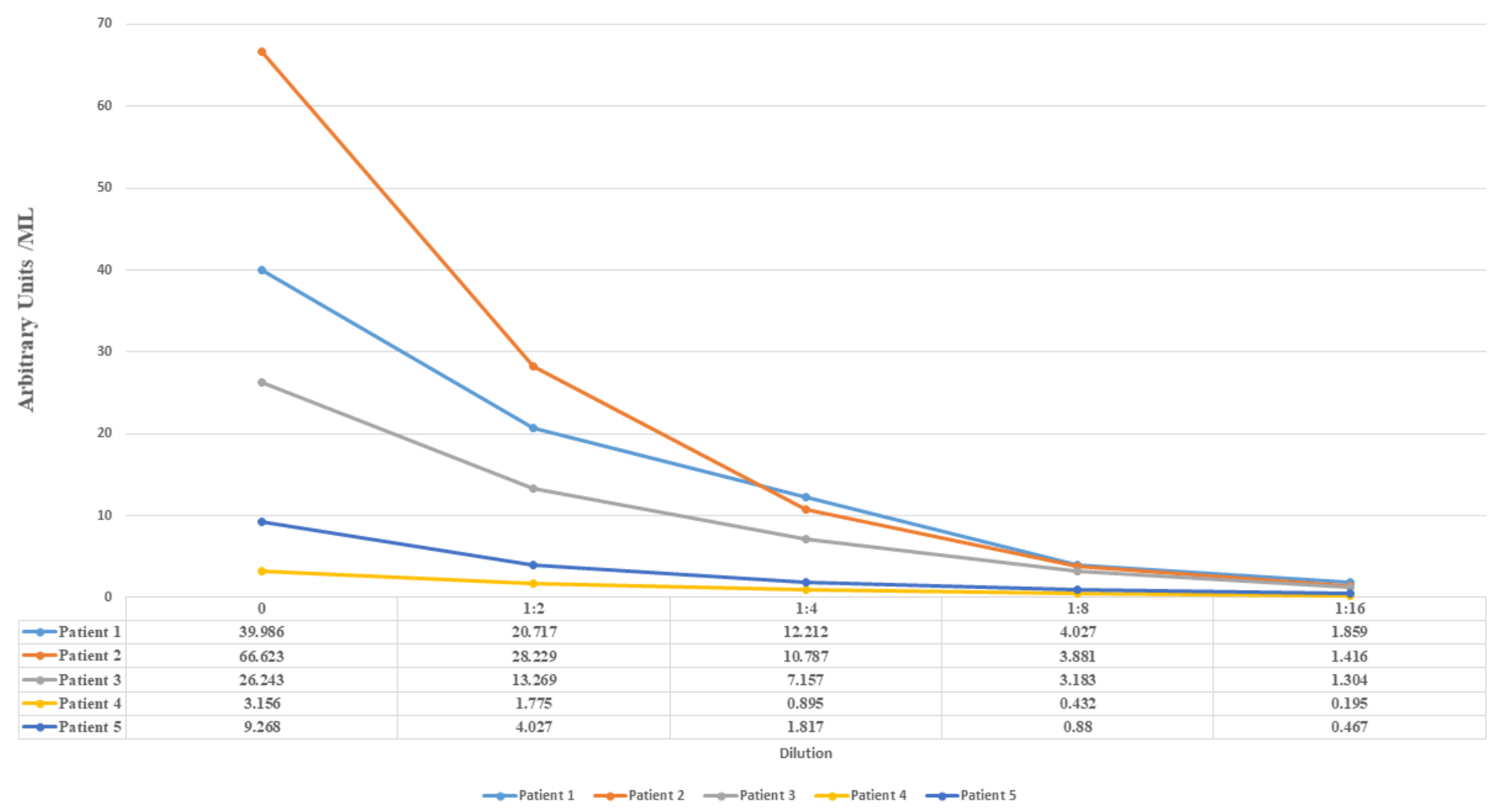


bioRxiv preprint doi: https://doi.org/10.1101/2020.06.26.174672; this version posted June 29, 2020. The copyright holder for this preprint (which was not certified by peer review) is the author/funder. All rights reserved. No reuse allowed without permission.

Fig. 2

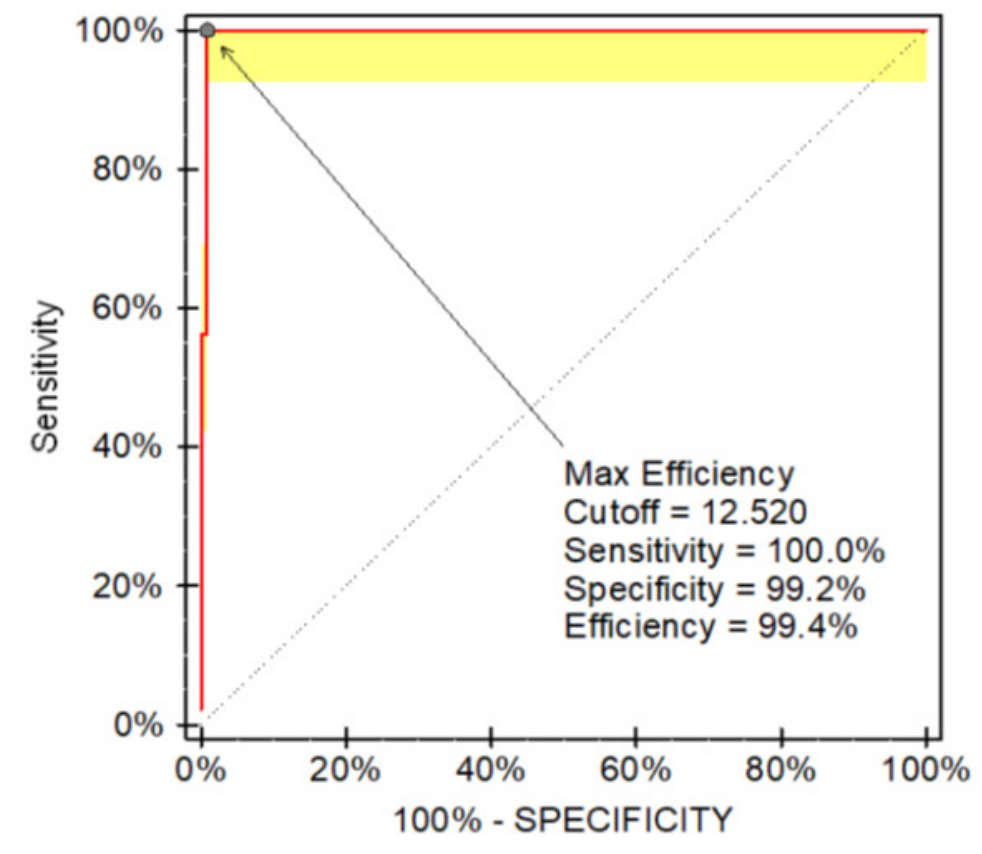


bioRxiv preprint doi: https://doi.org/10.1101/2020.06.26.174672; this version posted June 29, 2020. The copyright holder for this preprint (which was not certified by peer review) is the author/funder. All rights reserved. No reuse allowed without permission.

Fig. 3

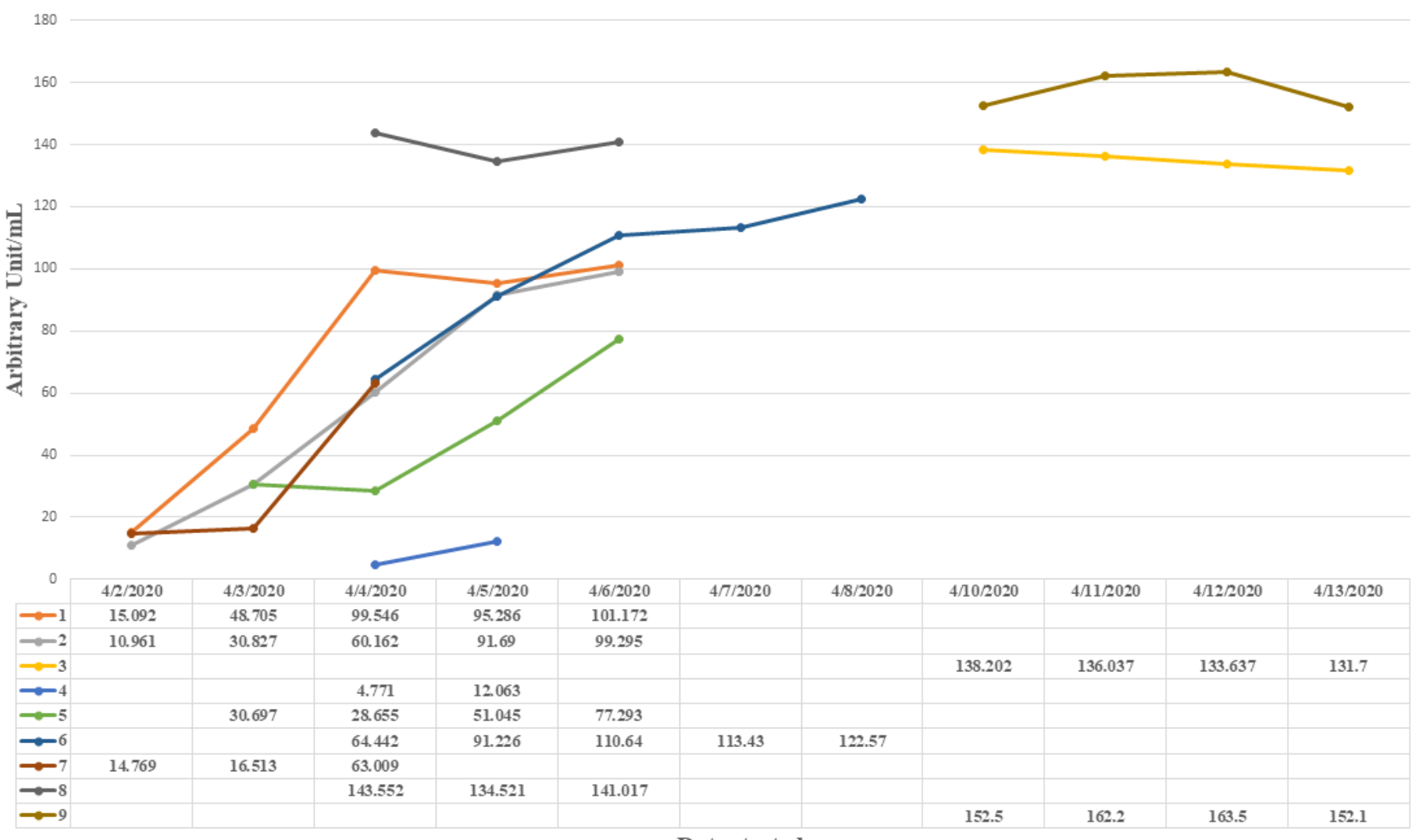

Dates tested 
Table 1A: Comparison of rtRT-PCR and serum IgG using a lower (13 AU/mL) cut off

\begin{tabular}{|c|c|c|c|}
\hline & \multicolumn{3}{|c|}{ rtRT-PCR } \\
\hline \multirow{3}{*}{ IgG } & & Positive & Negative \\
\hline & Positive & 15 & 33 \\
\hline & Negative & 0 & 119 \\
\hline
\end{tabular}

\begin{tabular}{|c|c|}
\hline Sensitivity & $100 \%$ \\
\hline Specificity & $78 \%$ \\
\hline PPV & $31 \%$ \\
\hline NPV & $100 \%$ \\
\hline
\end{tabular}

Table 1B: Comparison of rtRT-PCR and serum IgG using a higher (35 AU/mL) cut off

\begin{tabular}{|c|c|c|c|}
\hline \multicolumn{3}{|c|}{ rtRT-PCR } \\
\hline \multirow{3}{*}{ IgG } & Positive & 14 & 1 \\
\cline { 2 - 4 } & Negative & 1 & 151 \\
\hline & & & \\
\hline
\end{tabular}

\begin{tabular}{|c|c|}
\hline Sensitivity & $\mathbf{9 3 \%}$ \\
\hline Specificity & $99 \%$ \\
\hline PPV & $93 \%$ \\
\hline NPV & $99 \%$ \\
\hline
\end{tabular}

Serological data collected from outpatient specimens were compared with rRT-PCR results to determine assay performance characteristics. ROC analysis was performed to draw assay cutoff, data presented Table 1A and $1 \mathrm{~B}$ show performance characteristics at different levels of assay cutoffs. 
Serological and rRT-PCR testing in emergency department

Table 3A:

\begin{tabular}{|c|c|c|c|c|}
\hline $\begin{array}{c}\text { No. of COVID-19 } \\
\text { related clinical } \\
\text { symptoms }\end{array}$ & $\begin{array}{c}\text { Sositive } \\
(\mathbf{n = 1 8})\end{array}$ & $\mathbf{\%}$ & $\begin{array}{c}\text { Negative } \\
(\mathbf{n = 1 3 3 )}\end{array}$ & IgG \\
\hline $\mathbf{0}$ & 5 & 27.8 & 80 & 60.2 \\
\hline $\mathbf{1}$ & 4 & 22.2 & 30 & 22.6 \\
\hline $\mathbf{2}$ & 5 & 27.8 & 15 & 11.3 \\
\hline $\mathbf{3}$ & 4 & 22.2 & 5 & 3.8 \\
\hline $\mathbf{4}$ & 0 & 0.0 & 3 & 2.3 \\
\hline
\end{tabular}

Table 3B:

\begin{tabular}{|c|c|c|c|c|}
\hline $\begin{array}{c}\text { No. of COVID-19 } \\
\text { related clinical } \\
\text { symptoms }\end{array}$ & $\begin{array}{c}\text { rtRT-PCR (n=151) } \\
\text { Positive }\end{array}$ & $\mathbf{\%}$ & $\begin{array}{c}\text { Negative } \\
(\mathbf{n = 1 4 7})\end{array}$ & $\%$ \\
\hline $\mathbf{0}$ & 0 & 0.0 & 88 & 59.9 \\
\hline $\mathbf{1}$ & 2 & 50.0 & 33 & 22.4 \\
\hline $\mathbf{2}$ & 1 & 25.0 & 16 & 10.9 \\
\hline $\mathbf{3}$ & 1 & 25.0 & 7 & 4.8 \\
\hline $\mathbf{4}$ & 0 & 0.0 & 3 & 2.0 \\
\hline
\end{tabular}

Data shown in the above tables represent specimens concurrently collected from ED patients. Specimens were tested for serum IgG and SARS-CoV-2 RNA as described in the methods. Electronic health records were reviewed for symptoms of COVID-19 as per CDC criteria and corresponding test results were noted for diagnosis of $S A R S-C o V-2$ infection in the ED cohort. 